\title{
McGregor Pedicled Groin Flap Surgical Technique for Reconstruction of Hand Skin Defects
}

\author{
Nazim Sifi Nacer Rouag Ammar Radjai \\ Orthopaedics and Traumatology Unit, EHS Salim Zemirli Hospital, El Harrach, Algeria
}

\section{Keywords}

Upper limb · Hand injury · Soft tissue defect · Reconstruction · Pedicled flaps · Groin flap

\begin{abstract}
McGregor flap is an axial pattern distant flap, also known as pedicled groin flap. It is a highly reliable flap for large tissue defects of the hand (dorsal or palmar surfaces), the wrist, or the forearm, up to the elbow. Based on its own vascular pedicle, with a constant blood supply, it can be easily transferred with acceptable aesthetic outcomes. Therefore, the McGregor flap remains a flap of choice in the therapeutic arsenal of emergency hand surgery, especially when no other solution can be offered. In the following description, we try to present the anatomical landmarks as well as the different operating steps allowing the safe and easy performance of the aforementioned flap.
\end{abstract}

\section{Introduction}

The coverage of hand and forearm soft tissue defects is a surgical challenge. Its approaches and techniques have continued to progress, particularly with the advent of free flaps and microsurgery $[1,2]$. However, mastering microanastomosis techniques is not yet within the reach of all teams, especially in developing countries. This is why the groin flap remains a valuable technique in the therapeutic arsenal of reconstructive surgeries of the hand and the forearm, in an emergency context [3], for primary coverage of soft tissue before secondary microsurgical procedure or as a salvage procedure if the free flaps fail [4]. It was originally described by McGregor [5], following his work with Jackson [6] on the vascularization of the

\section{Karger $\stackrel{\text { ! }}{=}$}


deltopectoral flap, as part of their search for a cutaneous territory with autonomous vascularization where the arteries and veins are very close at their origins and terminations, to propose the raising of a reliable and large skin flap, based on a clean and constant arteriovenous pedicle. The groin flap fulfilled these specifications enabling a remote autoplasty, the vitality of which is ensured by the vascular territory of the superficial iliac circumflex artery $[5,7]$, and allowing the coverage of large and complex soft tissue defects of the hand and forearm (wounds, traumatic amputations, degloving injury, burns, burn scars release, and tumor excision), especially when noble structures (tendons, nerves, and vessels) are exposed [1].

\section{Material and Method}

A 39-year-old male, a turner, presented with an open injury of the left hand following an industrial accident, resulting in an amputation injury. The lesions involved the index finger at the metacarpophalangeal joint associated with the section of the extensor tendons of the index, middle, and ring fingers and with a large skin defect, interesting the dorsal surface of the hand in zones 5 and 6 according to Verdan's classification (Fig. 1a, b).

\section{Surgical Technique}

The groin flap is an axial flap based on the superficial circumflex iliac artery, the anterolateral branch of the femoral artery. Its constant course is oblique, with an ascending and lateral direction, and its diameter at birth is $1.5-2 \mathrm{~mm}$. Arterial and venous anatomical variations of the pedicle are frequent. Under general anesthesia, our patient was placed in dorsal decubitus position with a block under the ipsilateral buttock for better access to the donor site. We identified the main landmarks which are the anterior superior iliac spine, the pubic bone, the inguinal ligament, and the femoral artery (Fig. 1c). A simple way to define the limits of this flap is based on the rule of " 2 fingers width" corresponding to the transverse diameter of the patient index and middle fingers at the level of the distal interphalangeal joint. This rule locates the theoretical origin of the superficial circumflex iliac artery out of the femoral artery in the interval of 2 fingers width below the inguinal ligament. The upper limit of the flap is at 2 fingers width above the inguinal ligament parallel to a line, defined by the course of the superficial circumflex iliac artery from its origin to the anterior superior iliac spine, which also represents the axis of the flap. The lower limit is at 2 fingers width below the emergence of the superficial circumflex iliac artery on a line also parallel to the aforementioned axis. The lateral limit is determined according to the size of the recipient site defect. Another way to draw this flap is to draw it astride the iliac crest $1 / 3$ of the flap above and $2 / 3$ below [8]. We first performed debridement and preparation of the recipient site: initially by completing
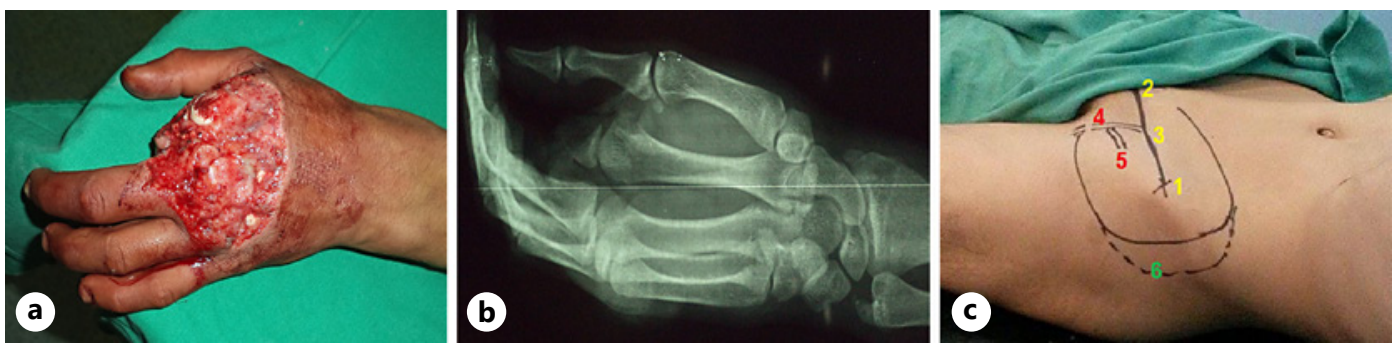

Fig. 1. a Clinical aspect of the traumatic injury. $\mathbf{b}$ Radiological appearance of the lesion. $\mathbf{c}$ Landmarks of the flap: anterior superior iliac spine (1), pubic bone (2), inguinal ligament (3), femoral artery (4), superficial circumflex iliac artery (5), and extension of the flap (6). 
Case Reports in Orthopedic Research

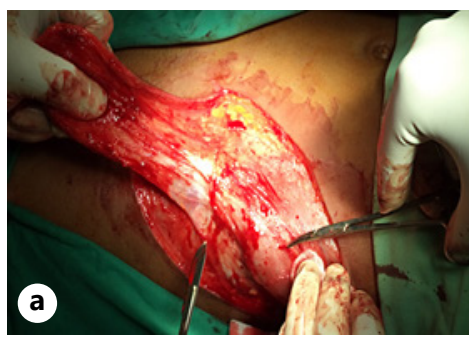

Fig. 2. a Raise of the flap. b Highlighting of the superficial circumflex iliac artery in the center of the flap (arrow). c Tubing of the flap base.

the amputation of the finger at the base of the 2nd metacarpal, according to Chase's method, and replacing it with the middle finger, allowing a better pollici-digital prehension, and then by the repair of damaged tendon structures. Subsequently, we observed an $11 \times 8 \mathrm{~cm}$ of tissue loss. An estimation of the size of the flap to be harvested compared to the tissue loss was also made. The exact evaluation of the actual tissue loss to be covered is essential, and it must always be estimated after a careful debridement in hand and forearm traumatic injuries and after the elimination of post-burn scar contractures [8]. After identifying the emergence of the superficial iliac circumflex artery by palpation of the common femoral artery, we raised the flap from lateral to medial and transferred all subcutaneous tissue while remaining suprafascial (Fig. 2a, b). But, near the sartorius muscle, we made sure to include the fascia in the flap in order to avoid damaging the arteriovenous package [3]. Careful dissection stops at the medial edge of the sartorius muscle, but it is possible to incise the skin further for greater elasticity. The lateral cutaneous nerve of the thigh is protected at the lateral edge of the sartorius. The measurement of the flap thus lifted is $20 \mathrm{~cm}$ long by $12 \mathrm{~cm}$ wide. The maximum size of the skin paddle can reach 30-35 cm of long axis by $15-20 \mathrm{~cm}$ wide. We then proceeded to the closure of the donor site with drain suction. This operation is easy to perform thanks to the skin elasticity of the upper segment, but in case of difficulty, we can use the detachment of the integuments from the abdominal wall and the flexion of the hip. At this step, some teams like that of Naalla et al. [9] do not prefer to tube the flap base; they keep the base of the flap narrow, so postoperative positioning is comfortable, and more reliable part of the flap is saved for subsequent insertion. But in most cases, including ours (Fig. 2c), tubing is carried out, preferably long, allowing the removal of the hand from the abdominal plane and a range of motion exercise of the hand, as well as the elbow and the shoulder [3]. A thinning can be performed at the distal area of the flap in case of excessive thickness, making sure not to damage the arterial network. In our case, we did not need to perform a thinning of the distal part of the flap. We then bring the hand to the inguinal region and adapt the flap to the defect before fixing the latter on the receiving site starting from the corner point (Fig. 3). Afterward, we sutured the more difficult posterior edge before the anterior edge. Beveling the fat at the edge of the skin before placing the flap decreases the tension at the suture line and the risk of necrosis of the edges [10]. At the end, we applied tulle gras dressings on all the sutures, changed every 3 days, and a support effectively maintaining the upper limb was made to avoid any stretching on the pedicle of the flap in case of restless waking up. The hip on the inguinal flap side was kept in flexion, by placing the lower limb on an independent splint [3]. Motion of the fingers was permitted as soon as the pain ceased, as well as that of the elbow and the shoulder. Ambulation was permitted on the 5th day after operation, and the division (Fig. 4) was done on the 3rd week [11]. Good preoperative planning helps avoiding the raising of a too large or too small flap as well as the preparation of a too long tubing causing a twist at its base or a too short one which would cause ischemia [1].

\section{Karger'}




\section{Case Reports in Orthopedic} Research

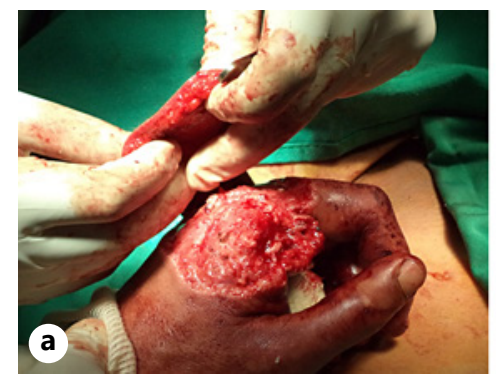

\begin{tabular}{l|l}
\hline Case Rep Orthop Res 2022;5:18-23 \\
\hline DOI: 10.1159/000521974 & $\begin{array}{l}\text { ○ 2022 The Author(s). Published by S. Karger AG, Basel } \\
\text { www.karger.com/cio }\end{array}$ \\
\hline
\end{tabular}

Sifi et al.: McGregor Pedicled Groin Flap

Fig. 3. a-c Coverage of the defect by the flap.
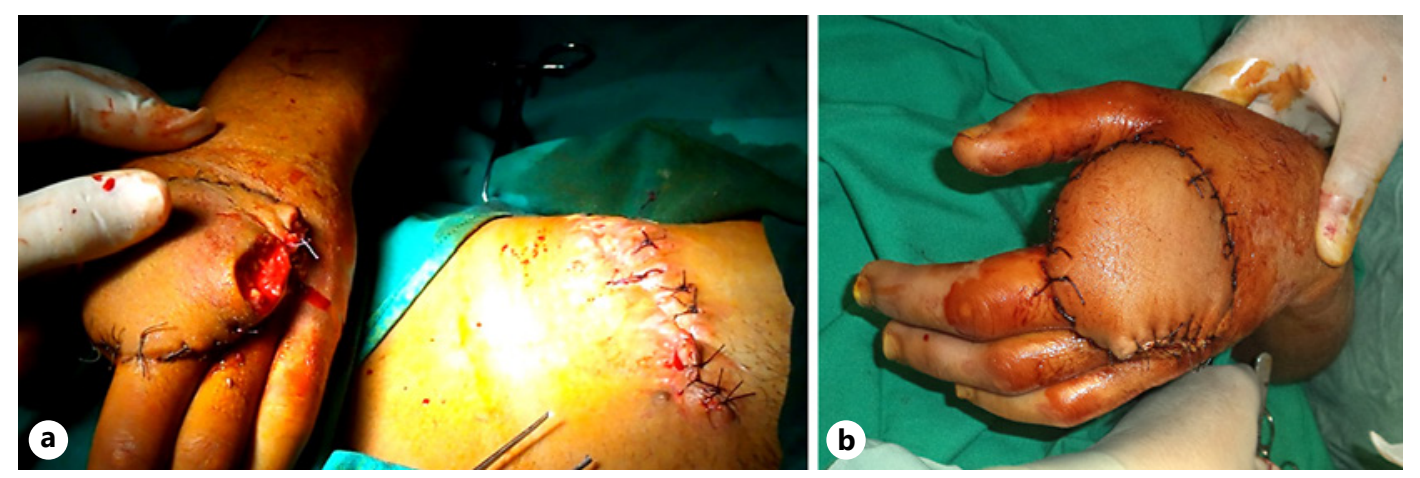

Fig. 4. a, b Division done on the 3rd week.

\section{Results}

Besides a lack of sensibility in the reconstructed area, the postoperative was uneventful, with a very satisfactory functional and esthetic outcome. The patient returned to work 2 months later.

\section{Discussion}

Despite the increasing number of free and local flaps used to repair hand defects, the groin flap is still widely used $[12,13]$. Thanks to its long pedicle, the McGregor flap does not require an elaborate preoperative planning and can be put in place in emergency context even if Baron et al. [3] claim that the infectious risk, even minimal, remains correlated with the earliness of the operation. He adds that tubing the flap at its base limits maceration and therefore the risk of infection [5].

\section{Advantages}

It is a versatile flap, with a simple procedure [13], that can be carried out by less-experienced surgeons without microsurgery skills. It is reproducible, of excellent reliability, and does not sacrifice a muscle [13]. Its vascular reliability is due to the constancy of its vascular pedicle, even when anatomic variations exist $[1,8]$. Being a distant flap, it does not require a major vascular sacrifice as is the case with the Chinese flap, thus preserving the radial artery which may be necessary during subsequent reconstruction stages. It is widely used in emergency cases because of the quickness of the procedure (easily harvested and applied) and the large skin surface it can mobilize $[1,8,13]$. Indeed, this flap allows the raising of a skin paddle 
whose dimensions are larger than that of the regional flaps of the forearm enabling the coverage of extensive tissue loss with very soft tissue, ideal for joints. It can be three times longer than it is wide, which offers long tubing which allows early and active wrist and hand physiotherapy $[1,8,10]$. With a very low likelihood of retraction, it can indifferently cover dorsal or palmar defects [8], and the proximity of the iliac crest allows compound osteocutaneous groin flap harvest without creating another scar $[1,8]$. The donor site closure is direct, without skin grafting, leaving acceptable scar, easily hidden by underwear [8]. Finally, this flap has the advantage of transplanting hairless skin, even in hairy men, enabling cosmetic repair of the hands $[8,13]$.

\section{Disadvantages}

The groin flap has also a number of disadvantages, the main one being postoperative shoulder stiffness in elderly subjects [1] even though some authors have shown through their cases that this stiffness could be avoided with early physiotherapy. Indeed, the position of the upper limb during the necessary time before the division is uncomfortable $[4,10,14]$. This inclined position of the hand bandaged to the trunk for 3 weeks also complicates postoperative care and may cause transient hand edema, which quickly disappears thanks to the efficient venous and lymphatic drainage of the groin area [8]. One of the other disadvantages of the coverage with this flap is the need for multiple stages: division, then thinning(s), often mandatory in patients with a significant panniculus adiposus [10]. Finally, there is a loss of sensibility with this flap, which is all the more awkward when the thumb or other fingers are involved [14]. Some authors $[10,14]$ consider that in the era of microsurgery, the use of the groin flap keeps its indications and that when it is well performed, it is sometimes even preferable to the free flap, in particular for the coverage of multiple and complex hand injuries. Certain technical adaptations further optimize its ability to cover the dorsal and palmar surfaces of the hand and the forearm by producing a bilobed flap or by associating one of its possible extensions: inferior based on the descending branch of the superficial circumflex iliac artery, inferolateral based on the artery accompanying the lateral femoral cutaneous nerve, or superior based on the superficial inferior epigastric artery. In their study on the effectiveness of pedicled groin flaps in the treatment of hand defects, Goertz et al. [13] concluded that the results were overall positive and most patients satisfied.

\section{Conclusion}

The McGregor groin flap is an easy to perform and reproducible autoplasty which is reliable on the vascular level and does not require an elaborate preoperative planning, allowing the raise of a large flap. It is rapidly performed and requires a standard technical wherewithal within the reach of all surgeons. It offers a convenient coverage of large tissue defects of the hand, the wrist, and the forearm, in emergency context or elective surgery, on the condition of performing long tubing, compatible with an early physiotherapy. Every orthopedic surgeon should be able to perform it, all the more when no microsurgical possibility is available.

\section{Statement of Ethics}

This study protocol was reviewed and approved by the Scientific Committee and the Médical Council of Zemirli Hospital, in accordance with the principles of the Declaration of Helsinki, Approval No. HZ51-2019. Written informed consent was obtained from the patient for publication of the details of the medical case and any accompanying images.

\section{Karger'}




\section{Conflict of Interest Statement}

The authors declare that they have no competing interests.

\section{Funding Sources}

The authors declare that they have not received any financial support.

\section{Author Contributions}

S.N. and R.N. performed the device placement, the surgeries, and wrote the article. R.A. participated in the surgical interventions and in the postoperative management of the patients. All authors read and approved the final manuscript.

\section{Data Availability Statement}

All data generated or analyzed during this study are included in this published article.

\section{References}

1 Amouzou KS, Berny N, El Harti A, Diouri M, Chlihi A, Ezzoubi M. The pedicled groin flap in resurfacing hand burn scar release and other injuries: a five-case series report and review of the literature. Ann Burns Fire Disasters. 2017 Mar 31;30(1):57-61.

2 Hayashi K, Hattori Y, Sem SH, Sakamoto S, Doi K. A bilobed pedicled groin flap for reconstruction of forearm skin defects following replantation. Plast Reconstr Surg Glob Open. 2020 Mar 27;8(3):e2734.

3 Baron JL, Romain M, Louchahi N, Gomis R, Allieu Y. The inguinal pedicleflap in emergency traumatic hand surgery: value of the long pedicle permitting an early rehabilitation. Ann Chir Main Memb Super. 1991;10(5): 430-5; discussion 436.

4 Bajantri B, Latheef L, Sabapathy SR. Tips to orient pedicled groin flap for hand defects. Tech Hand Up Extrem Surg. 2013;17:68-71.

5 McGregor IA, Jackson IT. The groin flap. Br J Plast Surg. 1972;25(1):3-16.

6 McGregor IA, Jackson IT. The extended role of the delto-pectoral flap. Br J Plast Surg. 1970 Apr;23(2):173-85.

7 Smith PJ, Foley B, McGregor IA, Jackson IT. The anatomical basis of the groin flap. Plast Reconstr Surg. 1972 Jan;49(1):41-7.

8 Guiga M, Fourati MK, Meherzi A, Belhassine H, Nahali N, Darghouth M. Our experiences with pedicled groin flaps. Apropos of 80 cases. Ann Chir Main. 1988;7(1):79-84.

9 Naalla R, Chauhan S, Dave A, Singhal M. Reconstruction of post-traumatic upper extremity soft tissue defects with pedicled flaps: an algorithmic approach to clinical decision making. Chin J Traumatol. 2018 Dec;21(6): $338-51$.

10 Al-Qattan MM, Al-Qattan AM. Defining the indications of pedicled groin and abdominal flaps in hand reconstruction in the current microsurgery era. J Hand Surg Am. 2016 Sep;41(9):917-27.

11 Wray RC, Wise DM, Young VL, Weeks PM. The groin flap in severe hand injuries. Ann Plast Surg. 1982;9:459-62.

12 Choi JY, Chung KC. The combined use of a pedicled superficial inferior epigastric artery flap and a groin flap for reconstruction of a dorsal and volar hand blast injury. Hand. 2008;3:375-80.

13 Goertz O, Kapalschinski N, Daigeler A, Hirsch T, Homann HH, Steinstraesser L, et al. The effectiveness of pedicled groin flaps in the treatment of hand defects: results of 49 patients. J Hand Surg Am. 2012 Oct;37(10): 2088-94.

14 Sabapathy SR, Venkatramani H, Martin Playa P. The use of pedicled abdominal flaps for coverage of acute bilateral circumferential degloving injuries of the hand. Trauma Case Rep. 2015 Aug 29;1(3-4):25-31. 